\title{
TIME-SPATIAL CONTEXTUALITY, COMPLEXITY, AND INTEGRITY OF THE DEVELOPMENT AND COGNITION OF LANDSCAPE ECOLOGY (SELECTED THEORETICAL AND META-SCIENTIFIC ASPECTS)
}

\author{
FLORIN ŽIGRAI
}

Foreign visiting professor at Department of Geography and Applied Geoinformatics of the University of Prešov, e-mail: florin.zigrai@al.net

Received: $13^{\text {th }}$ June 2016, Accepted: $1^{\text {st }}$ August 2016

\begin{abstract}
The view of the development and cognition of landscape ecology should not be an isolated one. In order to comprehend the connection, complexity and cohesion of natural and social nature which influence the genesis, development and function of landscape ecology should be studied in time-spatial and landscape-ecological contextuality, complexity and integrity. This paper is devoted to the topic of time-spatial contextuality, complexity, and integrity of landscape ecology as a science approached from two points of view: firstly, the potential development of landscape ecology reflecting its object and approach of research and secondly, cognition of landscape ecology by landscape ecologists, i.e. subject of landscape ecological research. The mission of this paper is to at least partially enlighten so far less studied meta-scientific research field by means of selected theoretical and meta-scientific aspects.
\end{abstract}

Key words: Time-spatial contextuality, complexity, integrity, landscape ecology.

\section{INTRODUCTION}

Landscape ecology is aflexible scientific discipline; it is very dynamic as reflected by the development of its research object, approach, goal and subject on the empirical, methodical and theoretical/applied levels. It is the reason why this development should be seen in time-spatial contextuality, complexity, and integrity.

Contextuality, complexity, and integrity represent important inner meta-scientific properties and categories, which may greatly influence the mechanism of the development and cognition of landscape ecology. They are the key topics and issues of meta-landscape ecology (Žigrai, 2016). Research into contextuality, complexity, and integrity of landscape ecology in time and space is a complicated matter from the meta-scientific point of view and a successful solution requires, apart from other, intensive cooperation of several scientific branches e.g. philosophy (Kuhn, 1981; Viceník, 1988; Popper, 1997), geography (Mičian, 1999; Paulov, 2012) and landscape ecology (Forman \& Godron, 1993; Hobbs, 1997; Wiens, 1999; Wu \& Hobbs, 2002) These sciences help to draw the overall background and frame for the contextuality, complexity, and integrity of landscape ecology on the intra-, inter- and trans-disciplinary levels. 


\section{MATERIAL AND METHODS}

As background materials, which are important to prepare this syntetical contribution are the author's published arcticles dealing with meta-landscape ecology as a new ecological science (Žigrai, 2016), landscape ecology in theory and practice (Žigrai, 2010), preservation of authenticity and determination of identity of landscape ecology as one prerequisite of its future development (Žigrai, 2015), transfer of landscape ecological knowledge from theory to practice as a multi-stage process (Žigrai, 2013), some remarks to theoretical and meta-scientific principles of landscape ecology (Žigrai, 2009) and long-term ecological research sites in time-spatial context about theoretical and methodological notes to transformation, allocation and networking of long-term ecological research sites (Žigrai, 2001) on the one hand and other most important theoretical publications about landscape ecology e.g. landscape ecology (Forman, Godron 1993), future landscapes and the future of landscape ecology (Hobbs, 1997), toward a unified landscape ecology (Wiens, 1999), key issues and research priorities in landscape ecology: an idiosyncratic synthesis (Wu \& Hobb, 2002), geography, physical geography, landscape ecology: interpretation and function (Mičian, 1999). In addition to these, significant philosophical articles about science e.g. basic paradigms in the evolution of geography as science: an attempt at a brief identification (Paulov, 2012), the Structure of Scientific Revolutions (Kuhn, 1981), logic of scientific discovery (Popper, 1997) and disputes about character of methodology of science (Viceník, 1988) were also discussed.

As most important methods to prepare this contribution were excerption, comparison, deduction, induction and generalization of knowledge from above mentioned articles, which are significant to prepare selected theoretical and meta-scientific analytical and syntetical aspects of time-spatial contextuality, complexity, and integrity of the development and cognition of landscape ecology. In this way was possible to prepare internal structure of this contribution which consist of

$\rightarrow$ some connected notes on the general and landscape-ecological time-spatial contextuality, complexity, and integrity as the background to the development of science and landscape ecology,

$\rightarrow$ some remarks on the properties and mechanism of time and space effects as the background to time-spatial contextuality, complexity and integrity of landscape ecology, some remarks on the importance of time-spatial contextuality, complexity, and integrity for research into the development of landscape ecology,

$\rightarrow$ notes on the theoretical and methodical background of cognition in landscape ecology in time-spatial contextuality, complexity, and integrity,

$\rightarrow$ some remarks on the selected categories of cognition of landscape ecology, as well as some remarks on transformations of cognition of landscape ecology in time-spatial contextuality, complexity, and integrity.

\section{RESULTS AND DISCUSSION}

The most important results and discussion about meaning and carriers of time-spatial contextuality, complexity, and integrity of the development and cognition of landscape ecology are expressed in the following remarks.

Some remarks on the general and landscape-ecological time-spatial contextuality, complexity, and integrity as the background to the development of science 
Contextuality, complexity, and integrity are among the most important meta-scientific entities or characteristics, which influence the development and empirical, methodical, theoretical and meta-scientific formation of scientific disciplines including landscape ecology in time and space.

Simultaneously, they represent the inherent essence on which the synthesis of basic and applied scientific research is built. The scheme of division of the time-spatial and landscape ecological contextuality, complexity, and integrity is in Fig 1.

\section{Fig. 1: Scheme of divison of time-spatial and landscape ecological contextuality, complexity and integrity}

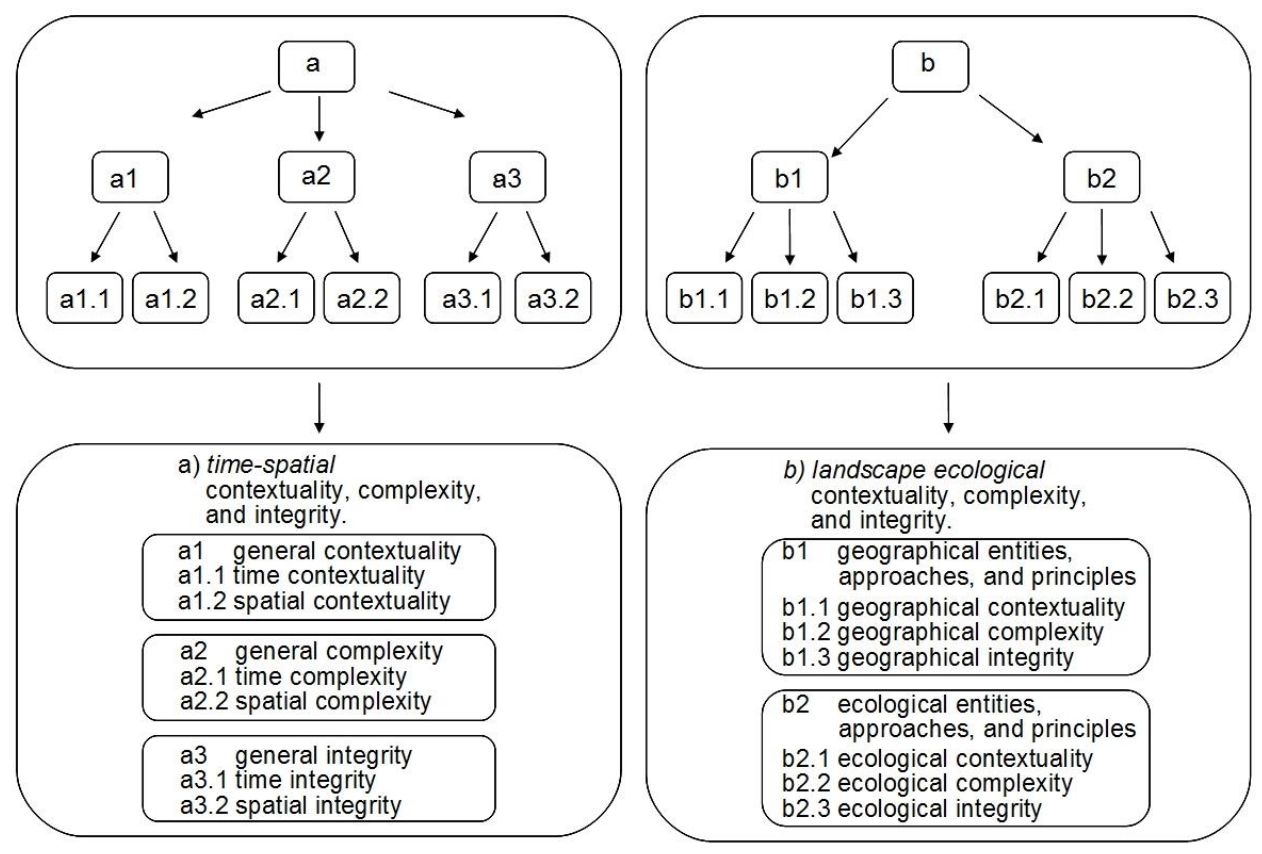

a 1) General contextuality is interpreted as certain connection, coherence, part or linkage to a given phenomenon, process and research in the corresponding context. Temporal and spatial contextuality represent universal properties which point to the coherence of a given particular, specific phenomenon and process in the time-spatial context. It is universal time-spatial coherence, which influences the scientific discipline in the frame of its theoretical and meta-scientific research.

a 1.1$) \rightarrow$ The carriers of time contextuality of a scientific discipline are individual time intervals, for instance, decades, when paradigms, scientific schools, and research trends emerged and developed regarding the nature and content of their research object and approach along with the definition of the scientific discipline.

a 1. 2) $\rightarrow$ The carrier of spatial contextuality of scientific discipline is spatial location of universities and scientific centres as the cores of gravitation fields where their individual paradigms, scientific schools, and research trends sprang and gradually spread from their topic level to the choric or from the local over the regional, national, continental and planetary levels. 
a 2) $\rightarrow$ The general complexity is interpreted as the rate of compound and comprehensiveness of a given phenomenon, process, and research. Time-spatial complexity represents universal properties which point to the comprehensiveness and complexity of the given particular, and specific phenomenon, process and research in time and space. For the purposes of this article it means the universal temporal and spatial complexity of the content of scientific discipline regarding its theoretical and meta-scientific research.

a 2. 1) $\rightarrow$ The carrier of the temporal complexity of scientific discipline is the rate or spectre of representation of individual temporal properties such as temporal accumulation potential, continuity and inertia, as well as the duration of the period of their action and effects which encourage the origins of a scientific discipline, its formation and the following development by means of its paradigms, views and research trends.

a 2. 2) $\rightarrow$ The carrier of spatial complexity of scientific discipline is the rate or spectre of representation of individual spatial properties such as spatial location and distance, as well as representation of topic-choric levels which contribute to the origins and formation of its individual schools, research trends and paradigms. These spatial properties also influence the origins of scientific discipline, its formation and development through its paradigms, scientific schools and research trends.

a 3) $\rightarrow$ General integrity is interpreted as certain wholeness, compactness and cohesion of the given phenomenon, process, and research. Temporal and spatial integrity represent universal properties which point to the completeness and cohesion of the given particular specific phenomenon and process in time and space. In case of this article it is the specific temporal and spatial integrity of scientific discipline on the level of its theoretical and meta-scientific research.

a 3.1) $\rightarrow$ The carriers of time integrity of scientific discipline are individual continuous intervals when its certain mutually cohesive scientific/research paradigms, trends and schools sprang and functioned undisturbed,

a 3. 2) $\rightarrow$ The carriers of spatial integrity of scientific discipline are scientific-research spatial fields formed by mutually cohesive individual paradigms, research trends and schools.

Carriers of temporal and spatial contextuality, complexity and integrity contribute with their content and nature to better comprehension of individual time-spatial connections, links, complexity, and wholeness of scientific discipline, including landscape ecology, as well as its developmental stages.

Some remarks to landscape ecological contextuality, complexity and integrity as the background to the development of landscape ecology

The inner structure of landscape ecology situated on the intersection of geography and ecology is certain qualitative/quantitative ratio of their individual geographical and ecological entities, approaches, and principles. Regarding this inner structure of landscape ecology it is appropriate to outline the relationship between contextuality, complexity, and integrity separately in the frame of geographical and ecological entities, approaches and principles as demonstrated in Fig. 1.

b 1) Geographical entities, approaches and principles are interpreted in the sense of their basic properties such as the spaciousness, wholeness, and synthesis, and differentiation within entities, spatial-structural-polycentric-geosystemic research approaches, principles of structure, function and stability of landscape, as well as landscape changes.

b 1. 1) $\rightarrow$ The carriers of geographical contextuality of landscape ecology are the connections and mutual information links between individual geographical disciplines 
which investigate the proper geographical phenomena, processes, entities, research approaches, and principles on their empirical, methodical, theoretical, meta-scientific and applied or didactic levels from their specific points of view.

b 1. 2) $\rightarrow$ The carrier of geographical complexity of landscape ecology is the spectre or the rate of representation of individual geographical disciplines which investigate the pertinent geographical phenomena, processes, entities, research approaches and principles on their empirical, methodical, theoretical, meta-scientific and applied or didactic level from their specific points of view.

b 1.3) $\rightarrow$ The carrier of the geographical integrity is the coalescence and cohesiveness of the individual geographical disciplines which study the appurtenant geographical phenomena, processes, entities, research approaches and principles on their empirical, methodical, theoretical, meta-scientific, and applied or didactic level from their specific points of view.

b 2) Ecological entities, approaches and principles are interpreted as their characteristic properties such as biotic-environmental, capacity of ecological interaction and integrity, trophic-energetic balance and biological productivity in the frame of entities, functional-processing-biocentric and reducing-ecosystem research approaches, as well as the principle of the movement of species, distribution of nutrients, energy flows and biotic diversity.

b 2. 1) $\rightarrow$ The carriers of ecological contextuality are the circumstances and mutual information links between individual ecological disciplines which investigate the pertinent ecological phenomena, processes, entities, research approaches, and principles on their empirical, methodical, theoretical, meta-scientific and applied or didactic levels from their specific points of view.

b 2. 2) $\rightarrow$ The carrier of ecological complexity is the spectre or rate of representation of individual ecological disciplines which study the pertinent ecological phenomena, entities, research approaches and principles on their empirical, methodical, theoretical, meta-scientific and applied or didactic levels from their specific points of view.

b 2. 3) $\rightarrow$ The carrier of ecological integrity is the coalescence and cohesion of individual ecological disciplines which investigate the pertinent ecological phenomena, processes, entities, research approaches and principles on their empirical, methodical, theoretical, meta-scientific and applied or didactic levels from their specific points of view.

Content and nature of the carriers of geographical and ecological contextuality, complexity and integrity contribute to better comprehension of individual connections, links, complexity, and coalescence between the geographical and ecological phenomena, processes, entities, research approaches, and principles of landscape ecology on its empirical, methodical, theoretical, meta-scientific, and applied or didactic levels. It simultaneously means a contribution to the preservation of authenticity and objective identity of landscape ecology (see Žigrai, 2015), and deeper cognition of landscape ecology along with the landscape-ecological synthesis and synthesis of landscape ecology in time-spatial contextuality, complexity, and integrity.

Based on the knowledge obtained from the above-cited analytical division and classification of time-spatial landscape-ecological contextuality, complexity, and integrity it is possible to proceed to its synthesis represented in Fig. 2.

This synthesis represents the general frame of research, development, and changes of landscape ecology. Time-spatial contextuality, complexity, and integrity in the upper left part of the scheme represents synthesis of the lower order composed of the analytical time and spatial contextuality, complexity, and integrity. Time contextuality, complexity, and integrity is expressed by certain temporal levels such as centuries and spatial contextuality, 
complexity and integrity is expressed by certain spatial levels such as local, regional, national, continental or planetary.

Likewise, in the right upper part of the figure landscape-ecological contextuality, complexity, and integrity represents the synthesis of the lower order consisting of analytical geographical and ecological contextuality, complexity, and integrity. Geographical contextuality, complexity, and integrity mean the corresponding mutual relationships between individual geographical disciplines while the ecological contextuality, complexity, and integrity mean the corresponding relationships between individual ecological disciplines.

The central lower part of the scheme shows the time-spatial-landscape-ecological contextuality, complexity, and integrity representing the syntheses of higher order. Synthesis of higher order consists of time-spatial and landscape-ecological contextuality, complexity and integrity which in turn represent the contextuality, complexity and integrity of the lower order syntheses.

Fig. 2: Scheme of time-spatial and landscape ecological contextuality, complexity and integrity

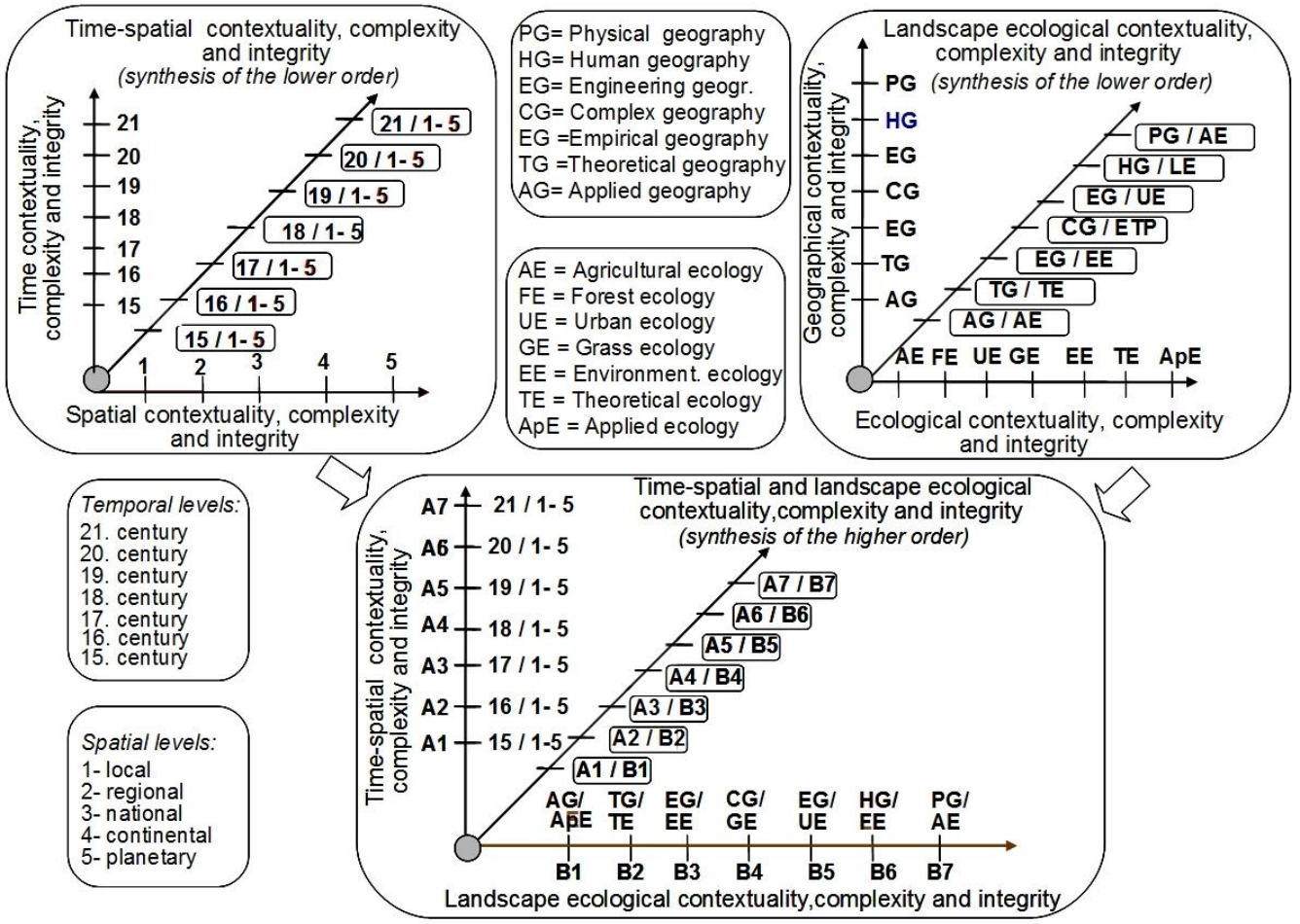

The scheme shows then that the time-spatial landscape-ecological contextuality, complexity, and integrity is the result of a combined multi-grade process from the analytical to the synthesised one. This combination reveals, apart from complexity of the process, its great information power and applicability of landscape ecology not only in the frame of the basic landscape-ecological research but also in everyday practice in an effort to solve ecological, environmental and socio-economic problems emerging in landscape. 
Time and space are two universal inseparable and mutually complementing media, which permanently, parallel and complementary act on time-spatial contextuality, complexity and integrity of the development and nature of landscape ecology.

Meanwhile the spatial change of landscape ecology takes place in the course of a specific time $\left(t_{1}, t_{2}, \ldots, t_{m}\right)$. In this case we talk about the time conditioned transformation of landscape ecology. The temporal changes are simultaneously linked to the single points $\left(p_{1}, p_{2}, \ldots, p_{n}\right)$ of spatial allocation of landscape-ecological scientific and universities, institutes and their research trends, orientation and paradigm. That means spatially conditioned transformation of landscape ecology.

We base our analysis of the temporal dimension of transformation of landscape ecology in single properties of time, and especially in time accumulation potential, continuity and the inertia, because these are the time properties which enable the action of the proper mechanism of the time-conditioned transformation of landscape ecology.

$\rightarrow$ The most important property of the time accumulation potential is the ability to align information and elements of the following i.e. younger time moments to the preceding older ones $\left(t_{m} \rightarrow t_{m-l} \rightarrow \ldots t_{1}\right)$. Significance of the time accumulation potential in research of time-spatial contextuality, complexity and integrity of development and nature of landscape ecology lies in the fact that, as mentioned above, it gradually deposits single elements and information of the following younger events into the preceding older events (for more details see Žigrai, 2001).

In this way also the landscape-ecological time accumulation potential is formed. It consists of its empirical, methodical, theoretical, applied, didactic and informative parts. This potential inherent to time landscape-ecological contextuality, complexity, and integrity influences the present level of landscape ecology and makes it possible to accumulate certain landscape-ecological information power in its temporal contextuality, complexity, and integrity.

$\rightarrow$ Time continuity represents another important time property, the one when the elements and consequences of preceding events from time moment $t 1$ continue uninterrupted into the following time point $t_{2}, t_{3}$ to $t_{m}$. This also prevents unnecessary losses of landscape-ecological information.

Importance of this temporal property for the study of landscape ecology reposes on make possible permanent transition of one temporal layer of landscape-ecological information into another, which, besides other, allows us an easier research of landscape ecology development.

$\rightarrow$ Time inertia as the complementary component of time continuity represents some kind of its inner condition and simultaneously mechanism of its action. It is the effect of time inertia, which makes possible the proper transition of information of the preceding older event to the following newer one: $t_{l} \rightarrow t_{2} \rightarrow \ldots t_{m}$. It simultaneously contributes to a more fluent course of single events as the time of action is prolonged and the impact of the properties of the preceding interval on the following ones is milder. This effect of the inertia, which can act in positive, negative or neutral sense, can fade away and lose the effect. Importance of the time inertia for the study of development and transformation of landscape ecology lays in the fact that it makes possible for us to observe and understand temporal transition of its development and change.

The above quoted three properties of time act synergetic and not in isolated way. Continuity and inertia simultaneously represent some kind of "active" and "non-material" properties of time, which support and control rather "passive", "spiritual-material" time accumulation potential. These time properties with the "membrane" transfer mechanism of 
landscape-ecological information make possible the origin of "memory" of landscape ecology (Žigrai, 2013).

The analysis of significance of spatial dimension of the development and formation of landscape ecology is based on two principal properties of space, that is, position and distance. The fresh landscape-ecological knowledge and paradigms produced in the core of spatial allocation of certain landscape-ecological, scientific-research or didactic institution spread to the surroundings and resound in certain distance of this institution.

This is how gravitation field is created with the corresponding innovative landscape-ecological knowledge, research trend, and schools which produce certain spatial landscape-ecological paradigm. Forces of the neighbouring gravitation field of other landscape-ecological research-scientific or educational institution with other innovative landscape-ecological research trend, landscape-ecological school, paradigm or type of landscape ecology act on the border of this gravitation field.

Synthesis of temporal and spatial contextuality of the origins, development, and formation of landscape ecology is based on the combination of above-mentioned temporal and spatial properties. It leads to the deeper cognition of the development and formation of landscape ecology. Time-spatial syntheses of this kind are among the most demanding methodical, theoretical and meta-scientific tasks of landscape ecology which deserves further research.

Some remarks to the importance of time-spatial contextuality, complexity, and integrity for research into the development of landscape ecology

Landscape ecology should not be viewed in an isolated way in research of its genesis, formation, and function. It should be considered in its multiple theoretical and meta-scientific contextuality, complexity, and integrity. Only then the relevant complexities and cohesion of natural-social character which influence genesis, development, formation, and functions of landscape ecology can be properly comprehended. This consideration, taking into account above-mentioned remarks concerning the properties and mechanism of time and space effects as the background of time-spatial contextuality, complexity, and integrity and their effects on the origins and development of landscape ecology, suggests their importance for tracking of the development, formation, and the inherent character of landscape ecology which is in:

$\rightarrow$ Cognition of its holistic inclusion into the time-spatial, socio-economic and historical context (for instance in terms of its paradigms, philosophy, strategy, activity, methodical approach, and its intra-, inter- and trans-disciplinary nature, etc.);

$\rightarrow$ identification of the rate of its complexity, that is, spectre of representation of individual geographical and ecological disciplines with their proper entities, research approaches and theoretical principles in the frame of landscape ecology, which address a particular issue of basic and applied landscape-ecological research;

$\rightarrow$ identification of the rate of its integrity, that is, inseparability of geographical and ecological entities, approaches and principles in frame of landscape ecology which are the key conditions for maintaining its authenticity, unity and sustainable development;

$\rightarrow$ strengthening of the objectivity of its empirical methodical, theoretical and applied landscape-ecological syntheses involved with landscape research and meta-scientific synthesis dealing with landscape ecology as a scientific discipline and

$\rightarrow$ achievement of a deeper picture of the relationship between universal time-spatial and specific landscape-ecological contextuality, complexity, and integrity, giving landscape ecology greater information power not only in basic landscape-ecological research but also in 
practical solutions to ecological, environmental and socio-economical problems emerging in landscape.

Some remarks on the importance of time-spatial contextuality, complexity, and integrity for research into the development of landscape ecology

The above-cited general notes on time-spatial and landscape-ecological contextuality, complexity, and integrity and its significance for the development and transformation of landscape ecology suggest, apart from other, high level of complexity of the issue. Its successful solution requires close cooperation between landscape ecology and other sciences which might be as well classified into four groups:

$\rightarrow$ a) "temporal" scientific disciplines involved with the phenomenon of time in the relationship to their specified landscape-ecological content both in narrower and broader sense. These include, for instance, historical landscape ecology, historical ecology, dynamic ecology, evolution ecology, recovering ecology, history, historical geography, and other. The contribution of "temporal" scientific discipline with the help of above-quoted temporal properties is in the research of the origins, development, formation, and transformation of landscape ecology along with the definition of its scientific-historical "memory".

$\rightarrow$ b) "spatial" scientific disciplines studying the phenomenon of space in the relationship to their specialised landscape-ecological content both in the narrow and broader interpretation. These disciplines include first of all geography and within it the physical and human geographies, spatial ecology, learning about spatial planning, learning about land use, and other. The contribution of "spatial" scientific disciplines for landscape ecological research is in approximation of their spatial contextuality, complexity, and integrity on different topic-choric levels making possible their interpretation in the form of, for instance, notional and content-bound heterogeneity of landscape ecology, and well its multiple definitions.

$\rightarrow$ c) "relational" scientific disciplines involved with the interaction between living organisms and the environment on different topic-choric levels. Here belong the autecology, demecology, synecology, agrarian ecology, forest ecology, urban ecology, grassland ecology roofed by landscape ecology. The contribution of the "relational", that is, ecological and environmental scientific disciplines for the landscape-ecological research is first of all in bolstering the ecological-merological approaches to landscape research and strengthening of spatially more comprehensively conceived landscape ecology with important specific information. These make it possible to compose the overall ecological picture of landscape ecology and to conceive its regularities and general laws (more in Žigrai, 2010).

$\rightarrow$ d) "structural" scientific disciplines involved with the abstract research of the structure phenomenon as such in the relationship to their specialized landscape-ecological content both in the narrow and broader interpretations. These disciplines include first of all mathematics, geo-information science, cybernetics, systemic theory, and contextology.The contribution of "structural" scientific disciplines for the research into origins, development and formation of landscape ecology is first of all in formalisation of the relationships, linkages, regularities and general laws in the behaviour of structures with individual landscape-ecological entities, approaches, and principles and comprehension of their systems for deeper knowledge of time-spatial strengthening of landscape ecology. 
One of the possible theoretical and methodological approaches, deeper cooperation of time, spatial, relational and structural scientific disciplines in landscape-ecological research is in its approximation of empirical knowledge and information, theoretical bases and methodical instrumentations of the above-mentioned groups of scientific disciplines with the help of their intersection areas as a nucleus of the new central discipline which should study time-spatial contextuality, complexity, and integrity of the development of landscape ecology. It will lead to a more objective and more exact research of the development and formation of landscape ecology taking into account their time-spatial and landscape ecological contextuality, complexity, and integrity (Fig. 3).

Notes on the theoretical and methodical background of cognition in landscape ecology in time-spatial contextuality, complexity, and integrity

Cognition of landscape ecology as the scientific discipline in its time-spatial contextuality, complexity, and integrity is among its important theoretical and meta-scientific research fields. Meanwhile, other scientific disciplines, first of all epistemology and meta-landscape ecology, help cognition of landscape ecology. Cognition of landscape ecology by landscape ecologists should be comprehended as a permanently ongoing dynamic time-spatial process. The study of landscape ecology is linked to certain time interval and space and it reflects the concluded status of cognition. The resulting product of cognition of landscape ecology is the landscape-ecological knowledge as a specific kind of scientific knowledge objectively and subjectively generated by landscape ecology by means of their empirical, methodical, theoretical, applied, didactic and meta-scientific landscape ecological and meta-scientific research approach and apparatus.

Fig. 3: Scheme of the nucleus of science dealing with time-spatial and landscape ecological contextuality, complexity and integrity of the development of landscape ecology, which lies in the intersection area of temporal, spatial, relational and structural sciences

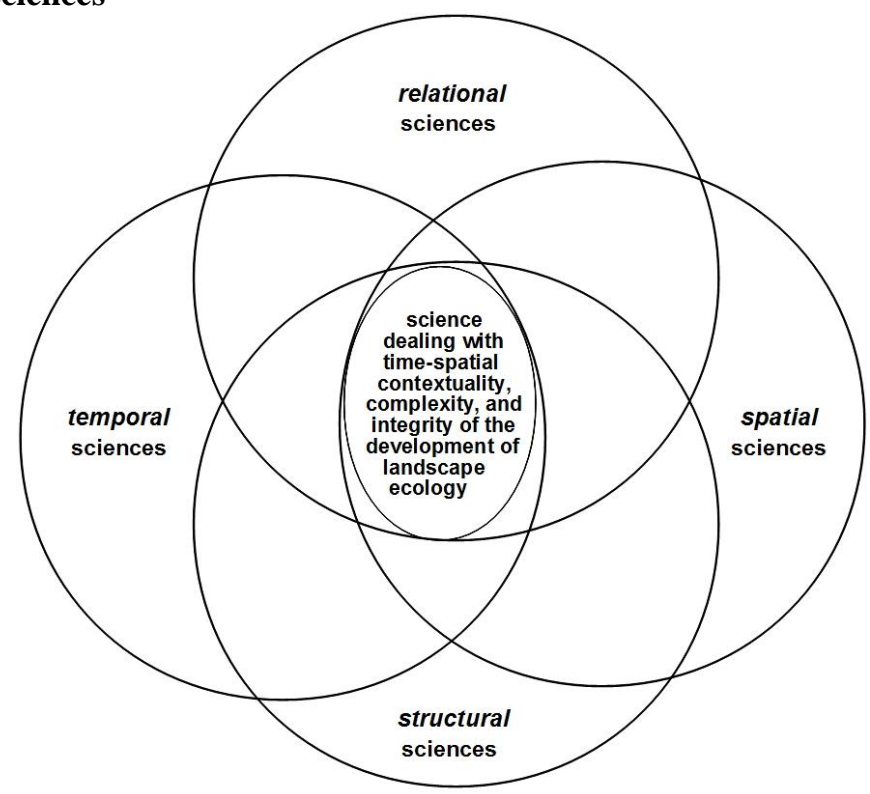


The issue of contextuality, complexity, and integrity of the origins, development and aim of cognition of landscape ecology in time and space has not been given much attention. As already said, contextuality, complexity, and integrity represent important inherent meta-scientific proprieties and categories, which to great extent influence the mechanism of the origins, development, and formation, as well as function of cognition of landscape ecology. Research into the contextuality, complexity, and integrity of cognition of landscape ecology in time and space is, from the meta-scientific point of view, a complicated matter where the successful solutions require, beside other, intensive cooperation of several scientific disciplines as suggested in the preceding sub-chapter. These sciences help us to create the overall background and a frame for contextuality, complexity, and integrity of cognition of landscape ecology on its intra-, inter- and trans-disciplinary levels.

The mission of this sub-chapter is then a brief characterisation of theoretical and meta-scientific background of cognition of landscape ecology in time-spatial contextuality, complexity, and integrity and briefly to analyse selected categories of the cognition of landscape ecology, as well as to outline the temporal and spatial changes in this area.

The focus of the research object of meta-landscape ecology is the landscape ecology itself as a science. This research object of meta-landscape ecology is involved, beside other, with its authenticity, identity, syntheses and principles of landscape ecology.

Simultaneously, less attention is paid to the subject of landscape-ecological research itself, that is, to landscape ecologists, particularly the way they cognize landscape ecology and what are the metamorphoses of their cognition in time-spatial contextuality, complexity, and integrity. Epistemology, the science with the aim to universalise the generation, structure, character, processes, transfer, and storage of knowledge, is involved with the theoretical question of cognition. There is certain relationship between landscape ecology, meta-landscape ecology and cognition, which can be first of all expressed by the meta-scientific information flow represented in Fig. 4.

Fig. 4: Scheme of information flow among meta-scientific cognition, meta-landscape-ecological cognition, landscape ecological cognition and landscape ecological cognition of science

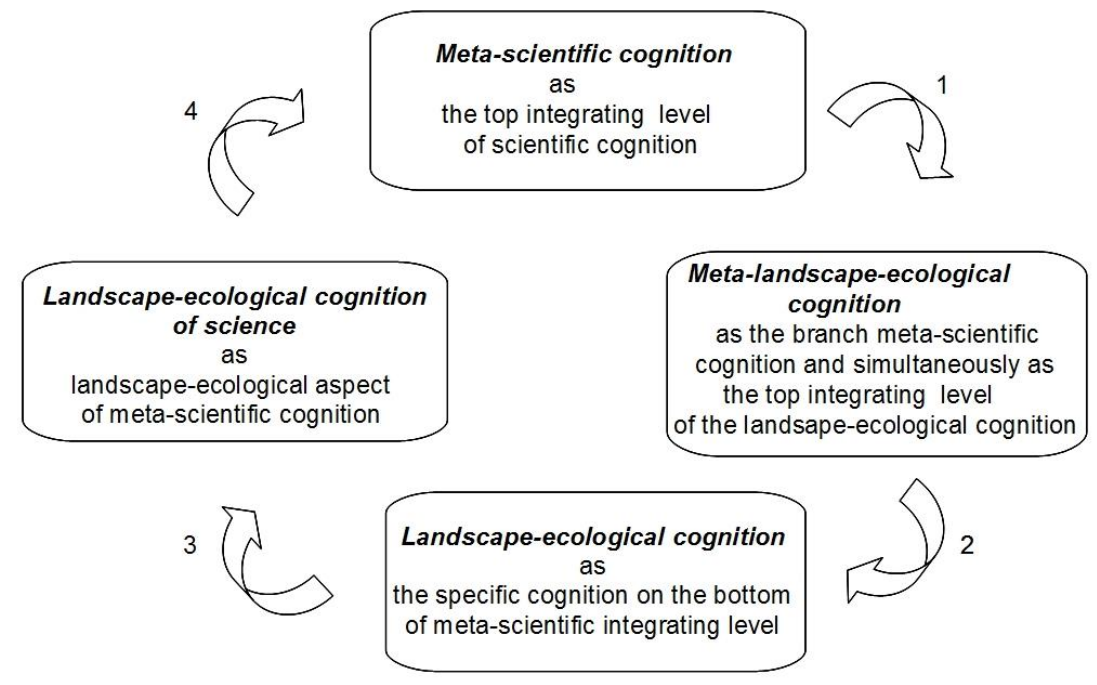

1, 2 = deductive approach of cognition

$3,4=$ inductive approach of cognition 
This scheme indicates that:

$1) \rightarrow$ the meta-scientific cognition is the top integrating and generalising level of scientific cognition, that is, a sum of cognition of all scientific disciplines;

2 ) $\rightarrow$ part of the overall meta-scientific cognition on the lower meta-scientific level is special cognition, in our case meta-landscape-ecological one which is the top integrating level of the landscape-ecological cognition itself, and

$3) \rightarrow$ landscape-ecological cognition as the specific cognition on the bottom meta-scientific integrating level contributes to the saturation of landscape-ecological science as

$4) \rightarrow$ the landscape-ecological aspect of meta-scientific cognition. This also is where the meta-scientific information circulating flow between the meta-scientific and meta- landscape ecological cognition and landscape-ecological cognition of science closes.

The second approximation between landscape ecology and cognition is expressed by the mutual relationship between landscape ecology and epistemology as illustrated in Fig. 5 .

The scheme indicates that in the cross-section area of landscape ecology and epistemology overlaps the landscape-ecological spatial and functional aspect where the main research object is landscape and the relationship between landscape and man with the epistemological cognitive-knowledge aspect where the main research object is cognition and knowledge.

These aspects, depending on the rate of their representation, fill the inner essence of either epistemological landscape ecology or landscape-ecological epistemology. Meanwhile, the main research object of epistemological landscape ecology as a branch of landscape ecology is landscape-ecological reality with special regard for its cognition by landscape ecologist.

Fig. 5: Scheme of the landscape ecological and epistemological-cognitive science system

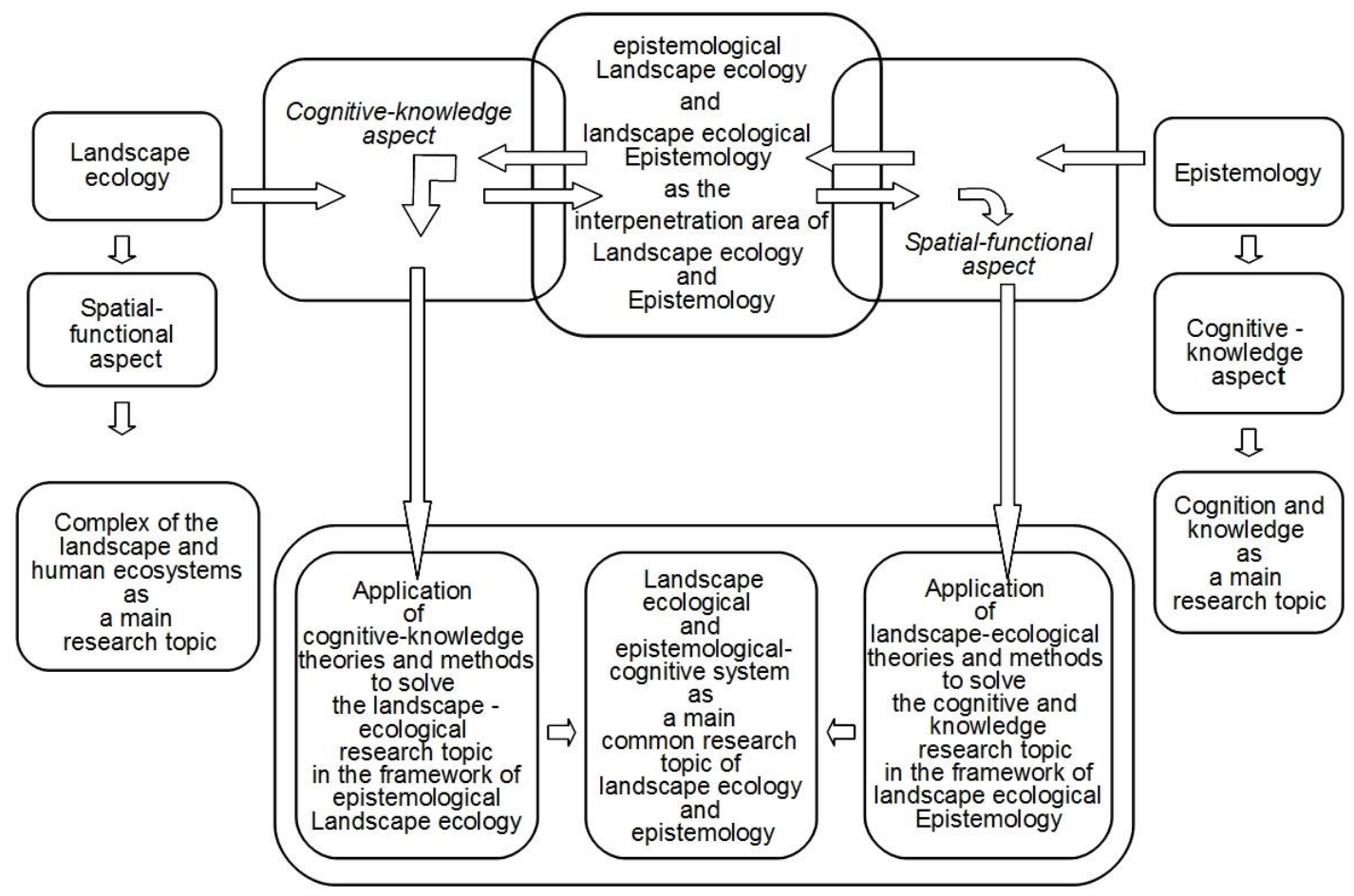


The focus of attention of landscape-ecological epistemology as the epistemological discipline is the research into cognition itself with regard to its landscape-ecological aspects such as spatial extension and functional relationships of cognition and knowledge. Simultaneously, landscape ecological theory and methods are used in the study of epistemological research issues in the frame of landscape-ecological epistemology and vice versa, epistemological theories and methods are applied to the solutions of landscape-ecological research problems in the frame of epistemological landscape ecology. The result of these mutual effects between landscape ecology and epistemology is, apart from other, strengthening the common research object, that is, landscape-ecological and epistemological systems with the help of above-mentioned landscape-ecological and epistemological aspects, theories and methods.

The above-quoted brief remarks also suggest the main tasks of epistemological landscape ecology which dwell first of all in the awareness of the development outlooks in cognition of landscape ecology, conception of its paradigms, research of generation and transfer of landscape-ecological knowledge, as well as in increased social acceptance and relevancy of landscape-ecological cognition in time-spatial contextuality, complexity, and integrity.

Successful solution of utmost complexity of such issue as is cognition of landscape ecology in time-spatial contextuality, complexity, and integrity also requires, beside close cooperation between landscape ecology itself and epistemology, an intensive exchange of information with other sciences involved with time-spatial questions of cognition of their corresponding realities. The core of the science that should investigate the time-spatial contextuality, complexity and integrity of cognition of landscape ecology and its conditions is situated in the cross-section of the temporal, spatial, relational and cognitive scientific disciplines

\section{Some remarks on the selected categories of cognition of landscape ecology}

The most important categories of landscape-ecological cognition is the object, that is, what is cognized, the way how it is cognized, i.e. the subject matter, the aim of landscape-ecological cognition, that is, why it is cognized, subject of landscape-ecological cognition, that is, who cognizes, and the contribution to landscape-ecological cognition, that is, what has been recognized.

The subject of cognition of landscape ecology that is landscape ecologist appears in these relationships as an active element of cognition that influences other rather passive categories of cognition. This is the reason, why, also regarding the theme of this sub-chapter, the landscape ecologist as the subject of cognition of landscape ecology in the flow of his/her knowledge, capacities, properties and skills is in the centre of interest because his/her mission is to successfully recognize landscape ecology in its time-spatial contextuality, complexity and integrity. This relationship is mostly interpreted in one-way sense, that is, in the direction of contribution of landscape ecologist on the empirical, methodical, theoretical or didactic and applied levels.

However, a circumstance that is it possible to perceive the relationship between the object and subject of cognition of landscape ecology in an information feedback must be also mentioned. It is from the point of view of contribution of landscape ecology to the development of the ecologist's personality as the subject of landscape-ecological cognition. Meanwhile, this contribution means not only the broadening of the knowledge-cognitive horizon and skills of landscape ecologist in natural-social contextuality, complexity, and integrity but also strengthening of their moral and volitive characteristics necessary for the demanding scientific and pedagogic activities. 
Cognition of landscape ecology by its subject, i.e. landscape ecologist, depends first of all on their scientific-research and didactic maturity connected with the achieved knowledge, capacities, and skills quoted in detail in study (Žigrai, 2015).

The contribution of landscape ecologist to further development of landscape-ecological cognition is in their originality, heuristic and innovative capacities on the following levels:

$\rightarrow$ Empirical: (fresh empirical knowledge of landscape ecology),

$\rightarrow$ Methodical: (new methodical approaches and procedures of cognition of landscape ecology),

$\rightarrow$ Theoretical: (new regularities and general laws in cognition of landscape ecology involved with landscape research from the ecological point of view),

$\rightarrow$ Meta-scientific: (new generalisations of cognition of landscape ecology as a scientific discipline on top integrating level),

$\rightarrow$ Applied: (new approaches to application of results of landscape-ecological cognition for the needs of basic and applied landscape-ecological research), as well as

$\rightarrow$ Didactic: (new approaches to mastering and development of landscape-ecological didactic knowledge, capacities, and skills necessary for the cognition of landscape ecology).

Subjective cognition of landscape ecology is the synthesised result of process of thoughts of landscape ecologist applying the obtained landscape-ecology knowledge, capacities and skills. Meanwhile, subjective cognition of landscape ecology is a dynamic process in the course of research and pedagogic career of landscape ecologist under the effect of the criteria and circumstances. These criteria and circumstances of subjective cognition of landscape ecology influence landscape ecologist's comprehension and study of the nature of landscape ecology, as well as the object, approach, subject, and aim of its research. They can also influence defining of landscape ecology itself. It can lead to greater diffusion of its definitions. It is the reason, why landscape ecologists as carriers of several different subjective cognitions of landscape ecology should strive to approximate for a more united comprehension and definition of landscape ecology as a scientific discipline.

Its main research object is precisely the landscape-ecological reality, it means the landscape studied form ecological point of view. Then the cognition of landscape ecology may become a binder that units the different views and activities of landscape ecologists in an effort to determine the authenticity and objective identity of landscape ecology situated in the cross-section of geographical and ecological entities, research approaches, and theoretical principles

The above notes on the theoretical and meta-scientific nature of cognition of landscape ecology suggest that it concentrates on:

$\rightarrow$ the integrating idiographic-nomothetic nature of landscape-ecological research on the level of landscape in the cross-section of geographical and ecological entities;

$\rightarrow$ relationships between landscape-ecological phenomena, processes and spatial structure, and on their relationships to human society on the spatial level of landscape;

$\rightarrow$ landscape-ecological, i.e. geographical and ecological, theoretical, methodical, empirical, and applied research approaches, and on

$\rightarrow$ the aim of landscape-ecological research, that is, acquisition of new empirical data, development of new methodologies, theoretical regularities and laws of landscape ecology as well as on the solution of natural and socio-economic problems in landscape.

The relationship between the object and approach of cognition of landscape ecology as well as landscape-ecological reality, which, beside other, determine preservation of the authenticity, identity, and sustainable development of landscape ecology, is also important for landscape ecologist. (more in Žigrai, 2015). 
The central object of cognition in landscape ecology, i.e. landscape ecology as scientific discipline and landscape-ecological reality, i.e. landscape researched from the ecological point of view and in relation to human society now expands with the increasing ecological and environmental and socio-economic problems accompanied by time-spatial transformation of landscape. The landscape ecologist attempts, in the frame of the inner structure of cognition of landscape ecology, to contribute to its development and simultaneously reacts to the changing object of cognition by the development of its subject matter and approach and the methodical instruments. Meanwhile, the balance between cognition of landscape ecology in the frame of both narrowly and broadly interpreted landscape ecology but also between the development of the object and the subject matter cognition of landscape ecology. In this context landscape ecologist also tries to acquire new empirical, methodical, theoretical and applied knowledge and experience in the sense of the above quoted scientific content. But it also brings the need to maintain the basic character of the research approach to the cognition of landscape ecology when solving natural and social problems in landscape from the objective and authentic landscape-ecological point of view.

Some remarks on transformations of cognition of landscape ecology in time-spatial contextuality, complexity, and integrity.

Cognition of landscape ecology by the landscape ecologist is not a rigid or impulsive activity. It is a continuous process in universal time-spatial and specialised, in our case landscape-ecological, contextuality, complexity and integrity.

The cognition of landscape ecology is subject to continuous changes caused by its inner structure particularly by the

$\rightarrow$ change of the landscape ecology itself,

$\rightarrow$ scientific development of the knowledge, skills and capacities of landscape ecologists, and

$\rightarrow$ with the development of a new items of cognition in the form of landscape-ecological, geo- bio- and human-ecological theoretical, methodical, empirical, and applied research approaches.

Meanwhile, cognition of landscape ecology is an ongoing uncompleted process and the knowledge is the resulting product of cognition. The cognitive process in time-spatial and landscape ecological contextuality, complexity, and integrity also helps deeper cognition of the order, differentiation, and conformity of landscape- ecological phenomena and processes.

As already said, cognition of landscape ecology is continuously subject to time-spatial changes interpreted in time-spatial contextuality, complexity and integrity of the development of landscape ecology.

In order to obtain and illustrative image of the time-spatial changes of landscape ecology cognition it is necessary to join the individual temporal and spatial characteristics. One of possible ways to join the temporal and spatial characteristics in relation to the development and formation of changes in cognition of landscape ecology is the representation of time-spatial anchoring of particular elements of landscape ecology cognition. This anchoring is determined by proper temporally and spatially co-ordinate. Better said, each element of landscape ecology cognition, particular product of which is landscape-ecological knowledge, is fixed within the intersection of time and space and illustrated in Fig. 6. 
Fig. 6: Scheme of time-spatial anchoring of landscape-ecological cognition in point " $A$ " in the intersection of time moment $t 1$ and spatial point $p 1$

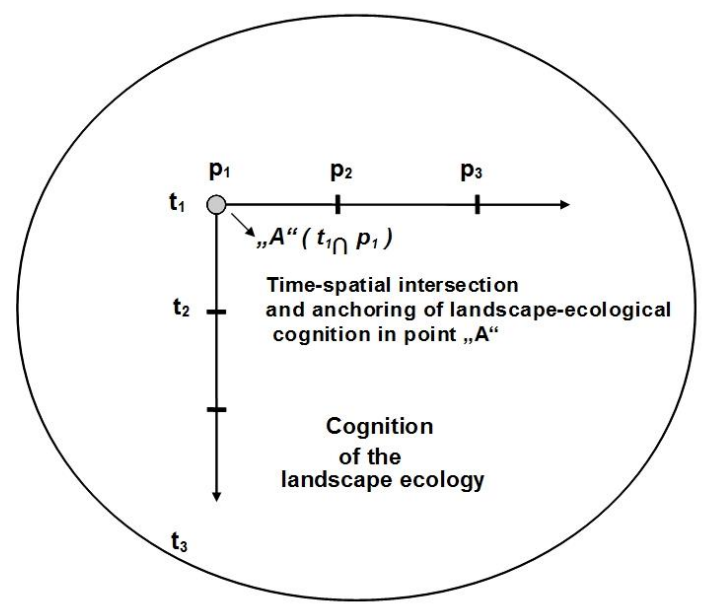

Certain set of these urban landscape elements with temporally and spatially close co-ordinates creates the corresponding time-spatial layers with cognition of landscape ecology. It is schematically illustrated in Fig. 7

Fig. 7: Time-spatial layers with cognitive knowledge of landscape ecology

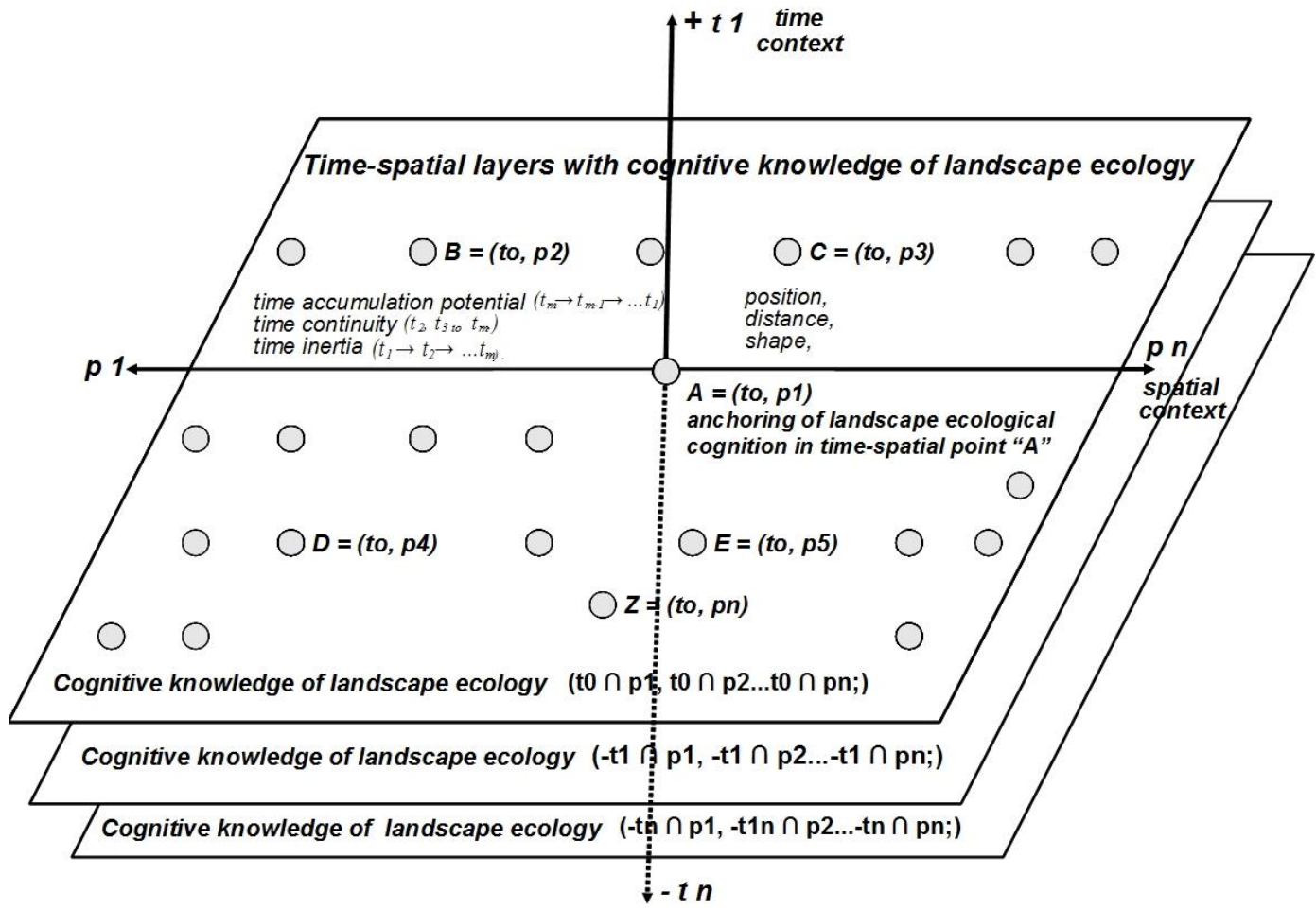


This figure depicts a kind of matrix of time-spatial relations of landscape-ecological knowledge elements suggests (beside other) that for instance, the oldest layers with landscape-ecological knowledge as a whole represent the multiplication or intersection of temporal moment $t 1$ with individual spatial points $p l$ to $p n$ of the proper landscape-ecological knowledge. It is possible to express with the formula:

$$
\begin{gathered}
n \\
\left(\prod \begin{array}{c}
t 1 p j \\
j=i
\end{array}\right.
\end{gathered}
$$

To the older layers of landscape-ecological knowledge the younger ones were added in the course of time. Meanwhile these layers overlap mutually without any clear transition from one to another. These layers are then created by spiritual elements of landscape-ecological knowledge in time and space. It is interesting enough that these spiritual elements are distributed by diffusion and innovation in space in discontinuous manner and more or less continuously in time.

The present landscape-ecological knowledge represent then a certain time compression or a „time briquette“ with overlapping spiritual elements or parts of fading out temporally „lower" of landscape-ecological knowledge with temporally „upper" and „the top“ layers which is expressed as:

$$
\prod_{\substack{i=1 \\ \text { tip } 1)}}^{m}
$$

Landscape ecology has simultaneously certain composition of these elements or mutually overlapping layers with landscape-ecological knowledge, which were formed or influenced by single landscape-ecological subjects, e.g. landscape ecologists. It means that landscape ecology is characterised by specific quantitative-qualitative structure of landscape-ecological knowledge, set in time-spatial context.

Every such „coded“ landscape-ecological knowledge has to be deciphered by progressive steps into its above-mentioned individual parts. This is how we more easily comprehend the development of landscape ecology together with transformation of its cognition. One of the typical traits of transformation of landscape ecology cognition is that its corresponding time-spatial co-ordinates of the individual landscape-ecological knowledge change as well. Spatial changes of the corresponding landscape ecological knowledge can take place only in the course of certain time

$$
\rightarrow \quad\left(t_{1} \cap p_{1}, t_{2} \cap p_{2, \ldots,} t_{m} \cap p n\right)
$$

while temporal changes of certain landscape ecological knowledge can take place also without their spatial change, for instance:

$$
\rightarrow \quad\left(t 1 \cap p 1 . t_{2} \cap p 1 \ldots t_{m} \cap p 1\right) .
$$

It is then the case of temporal ,ageing“ i.e. change of the inner qualitative property of particular landscape ecological knowledge without changing its spatial position. This circumstance facilitates inter alia also the origin of historic "memory" of landscape ecological cognition. 


\section{CONCLUSION}

The briefly presented spectre of selected aspects of theoretical and meta-scientific background of cognition of landscape ecology in time-spatial contextuality, complexity, and integrity and its transformations lead to the following generalisations:

$\rightarrow$ The recent, i.e. presently generated landscape-ecological empirical, methodical, applied, didactic, theoretical, and meta-scientific knowledge containing via the transfer and accumulation the majority of the preceding pieces of knowledge manifests the most substantial time contextuality, complexity, and integrity. Apart from other, it makes it possible to comprehend better the present state in the cognition of landscape ecology and to outline future development of landscape ecology. On the contrary,

$\rightarrow$ the older, in the past generated landscape-ecological empirical, methodical, applied, didactic, theoretical, and meta-scientific knowledge which only contains results of the preceding knowledge with smaller time-accumulation potential without taking into account the subsequent knowledge, manifests the most limited time contextuality, complexity, and integrity;

$\rightarrow$ The most substantial spatial contextuality, complexity, and integrity is proper to landscape-ecological knowledge of theoretical, meta-scientific and nomothetic nature in form of landscape-ecological regularities or laws ruling the top choric levels. This circumstance simultaneously leads to the reduction of spatial isolation of individual research branches, scientific schools, and opinion in terms of cognition of landscape ecology on the one side and to decreased their diversity on the other;

$\rightarrow$ On the contrary, the landscape-ecological knowledge of empirical, idiographic nature linked to the topic level or choric level of lower order on the local or micro-regional level displays the smallest spatial contextuality, complexity, and integrity. It is characterised by a bigger spatial isolation of individual research branches, scientific schools and attitudes in terms of cognition of landscape ecology on one hand and simultaneously increased their diversity on the other.

The significance of the study of the cognition changes of landscape ecology in time contextuality, complexity, and integrity is inter alia in:

$\rightarrow$ more precise determination of authenticity of landscape ecology through deeper cognition of its substance consisting of the appurtenant landscape-ecological entities, approaches and principles ;

$\rightarrow$ in deeper penetration into landscape-ecological entities (spatial, wholeness, synthesis, order, differentiation, interaction, coincidence, balance, and the trophic nature);

$\rightarrow$ in closer links between the basic and applied landscape-ecological research on the empirical, methodical, didactic, applied and theoretical, meta-scientific levels;

$\rightarrow$ in an extended spectre of geographical (prevailingly spatial, polycentric, geosystemic ones, which explore prevailingly the horizontal-vertical, abiotic, biotic and human-geographical mutual relationships in landscape), as well as ecological (prevailingly functional, process-biocentric, and reduction-ecosystem which research prevailingly the vertical-horizontal, abiotic, biotic and human-ecological mutual relationships in landscape,

$\rightarrow$ in objectivising empirical, methodical, theoretical and applied landscape-ecological syntheses and meta-scientific synthesis of landscape ecology, as well as

$\rightarrow$ in closer determination of landscape-ecological principles such as the principle of species movement and energy flow, principle of biotic diversity, principle of nutrient redistribution, principle of landscape structure and function, principle of landscape changes and the principle of landscape stability, as well as 
$\rightarrow$ in closer determination of meta-scientific principles of landscape ecology such as the principle of indivisibility of ecological and geographical entities and approaches and the principle of stability of landscape ecology as explained in (Žigrai, 2009).

\section{REFERENCES}

Forman, R.T.T., Godron, M., (1993). Landscape ecology (in Czech). Academia Praha, 583 p. Hobbs, R. J., (1997). Future landscapes and the future of landscape ecology. Landscape and Urban Planning 37, 1-9.

Kuhn, T. S., (1981). The Structure of Scientific Revolutions (in Slovak). Vydavatel'stvo Pravda, Bratislava, 282 p.

Mičian, L'., (1999). Geography, physical geography, landscape ecology: interpretation and function. (in Slovak). Geografický časopis, Bratislava 51, (4), 331-345.

Paulov, J., (2012). Basic paradigms in the evolution of geography as science: an attempt at a brief identification.(in Slovak). Geografický časopis, 64, (2), 91-109.

Popper, K. R., (1997). Logic of Scientific Discovery (in Czech), Oikúmené, Praha, 618 p.

Viceník, J., (1988). Disputes about character of methodology of science, (in Slovak). Pravda, Bratislava

Wiens, J. A., (1999). Toward a unified landscape ecology. In J.A. Wiens and M.R. Moss (eds.) Issues in Landscape Ecology. (pp. 148-51). Snowmass Village: International Association for Landscape Ecology.

Wu, J. \& R., Hobb, (2002). Key issues and research priorities in landscape ecology: an idiosyncratic synthesis. Landscape ecology, 17, (3).

Žigrai, F., (2001). Long-term ecological research sites in time-spatial context.(Some theoretical and methodological notes to transformation, allocation and networking of long-term ecological research sites). Ekológia (Bratislava), 20, (2), 15-24.

Žigrai, F., (2009). Some remarks to theoretical and meta-scientific principles of landscape ecology (in Slovak) In V. Herber (Ed.), Fyzickogeografický sborník 7 (pp. 9-15). Fyzická geografie a trvalá udržitelnost. Brno: PF Masarykova univerzita.

Žigrai, F., (2010). Landscape ecology in theory and practice (selected theoretical and meta-scientific aspects). Ekológia (Bratislava), 29, (3), 229-246.

Žigrai, F., (2013). Transfer of landscape ecological knowledge from theory to practice as a multi-stage process. (Selected theoretical and meta-scientific aspects). Ekológia (Bratislava), 32 (3), 305-319. DOI:10.2478/eko-2013-0027

Žigrai, F., (2015). Preservation of authenticity and determination of identity of landscape ecology as one prerequisite of its future development (selected theoretical and metascientific aspects). Ekológia (Bratislava), 34, (2), 186-206.

Žigrai, F., (2016). Meta-landscape ecology as a new ecological science (selected meta-scientific aspects). In: Halada, L., Bača, A., Boltižiar, M. (eds.) 2016: Landscape and Landscape Ecology, (p. 25-35). Proceedings of the 17th International Symposium on Landscape Ecology, 27-29 May 2015, Nitra, Slovakia, Institute of Landscape Ecology, Slovak Academy of Sciences, Bratislava, branch Nitra, 372 pp. 